\title{
PENGARUH PELAKSANAAN SUPERVISI AKADEMIK TERHADAP PENINGKATAN KOMPETENSI PEDAGOGIK GURU DI SDN MARGOREJO VI/524 DAN SDN BARATAJAYA SURABAYA
}

\author{
Fauriza Rohmi ${ }^{1}$, Nafiah ${ }^{2}$ \\ Universitas Nahdlatul Ulama Surabaya \\ faurizarohmi9@gmail.com \\ nefi_23@unusa.ac.id
}

\begin{abstract}
The Effect of Academic Supervision to Improve Pedagogy Competency of Teacher of Margorejo VI/524 Elementary School and Baratajaya Elementary School of Surabaya. The headmaster is fully responsible for organizing education with teachers as class teachers. Teachers are required to master four competencies, one of which is pedagogical competence. However, not all teachers master these competencies, so it is the responsibility of the headmaster to conduct academic supervision. The activity is carried out in the form of class meetings / visits. Therefore, teachers can improve their pedagogical competencies. Researchers are interested in conducting research that aims to analyze the existence of academic supervision in SDN Margorejo VI / 524 and SDN Baratajaya Surabaya. Both schools are located in Surabaya. In addition, the study was conducted also, with the aim to examine the effect of the implementation of academic supervision on the pedagogical competence of teachers by using descriptive quantitative research methods and Spearman rank correlation with ordinal scale data. The population of the two schools is 102 respondents. Sample is 81 respondents with an error level of 0.05 . Observation with a questionnaire that has proven as valid and reliable. The analysis by using SPSS 21 . The study used two data analysis techniques, namely descriptive analysis and Spearman rank correlation analysis. The results showed that the two schools had carried out academic supervision activities to improve teacher pedagogical competence. The results obtained were 0.608 which means that the category is very good and good and classified as moderate correlation, with a significant correlation value of 0,000 $<0.05$. So the hypothesis in this study that $\mathrm{H} 1$ is accepted and $\mathrm{H} 0$ is rejected.
\end{abstract}

Keywords: teachers, academic supervision, and pedagogical competencies

\begin{abstract}
Abstrak
Pengaruh Pelaksanaan Supervisi Akademik Terhadap Peningkatan Kompetensi Pedagogik Guru Di Sdn Margorejo Vi/524 Dan Sdn Baratajaya Surabaya. Kepala sekolah bertanggung jawab penuh dalam penyelenggaraan pendidikan bersama para guru sebagai pengajar di kelas. Dalam proses tersebut, guru dituntut mampu menguasai empat kompetensi yang salah satunya yakni kompetensi pedagogik. Kompetensi tersebut bertujuan untuk mewujudkan suatu pembelajaran yang mendidik bagi peserta didik. Namun, tidak semua guru menguasai kompetensi tersebut, sehingga hal itu menjadi tanggung jawab kepala sekolah dalam mengadakan kegiatan supervisi akademik. Kegiatan tersebut dilakukan oleh kepala sekolah dengan memberi pembinaan, berupa rapat/kunjungan kelas. Dengan begitu, guru bisa meningkatkan kompetensi pedagogik yang dimiliki. Kegiatan tersebut dapat memperbaiki permasalahan dalam proses pembelajaran. Peneliti tertarik untuk melakukan penelitian yang bertujuan untuk menganalisis adanya keterlaksanaan supervisi akademik di SDN Margorejo VI/524 dan
\end{abstract}


SDN Baratajaya Surabaya. Kedua sekolah tersebut bertempat di Surabaya. Selain itu, penelitian dilakukan dengan tujuan untuk menguji adanya pengaruh keterlaksanaan supervisi akademik terhadap kompetensi pedagogik guru dengan menggunakan metode penelitian kuantitatif deskriptif dan korelasi rank spearman dengan data skala ordinal. Populasi dari dua sekolah yaitu 102 responden, sampel sebanyak 81 responden dengan taraf kesalahan 0,05 . Observasi dengan angket yang sudah teruji valid dan reliabelnya. Hasil analisa diperoleh dengan menggunakan SPSS 21 for Windows 2007. Penelitian menggunakan dua teknik analisis data, yakni analisis deskriptif dan analisis korelasi rank spearman. Hasil penelitian menunjukkan bahwa dua sekolah tersebut telah melaksanakan kegiatan supervisi akademik untuk meningkatkan kompetensi pedagogik guru. Hasil yang diperoleh sebesar 0,608 yang artinya berkategori sangat baik dan baik dan tergolong korelasi sedang, dengan nilai signifikan korelasinya sebesar $0,000<0,05$. Sehingga hipotesis pada penelitian ini yakni $\mathrm{H}_{1}$ diterima dan $\mathrm{H}_{0}$ di tolak.

Kata kunci: guru, supervisi akademik, dan kompetensi pedagogik.

\section{Pendahuluan}

Pendidikan termasuk segala sesuatu proses yang didasarkan pada kesadaran manusia secara sengaja dalam memperoleh pendidikan yang mampu mengembangkan potensi yang ada pada dirinya. Pendidikan berperan penting dalam kehidupan. Dimana dengan pendidikan, manusia dapat memiliki kecerdasan dalam bertingkah laku, beragama, dan bersosial dengan lingkungan dan negaranya. Sehingga alangkah baiknya jika pemberian penddikan dapat dilakukan sejak dini. Hal itu diharapkan dapat memudahkan manusia dalam bertindak dari ia mudah hingga tua. Pengertian tersebut sejalan dengan Undang-Undang Republik Indonesia No 20 Tahun 20013 tentang Sistem Pendidikan Nasional

Menurut UU Tahun 2003 pasal 3 tentang sistem pendidikan nasional menjelaskan bahwasanya terselenggaranya suatu pendidikan. Sehingga dalam penyaluran pendidikan, kepala sekolah berperan penting dalam pengelolaan penyaluran pendidikan.

Penjelasan tersebut menjelaskan bahwa pendidikan tidak akan tersalurkan jika tidak ada seorang kepala pendidik selaku pemimpin dalam pendidikan yang mana kepala sekolah tidak sendirian dalam melaksanakan hal tersebut, akan tetapi dengan bantuan guru. Hal itu yang disebut dengan supervisi.

Supervisi pengajaran ialah bentuk kegiatan yang dilakukan oleh pihak yang berwenang dalam hal ini adalah kepala sekolah yang berwenang memperbaiki segala permasalahan yang sering muncul dalam proses penyaluran pendidikan baik secara individu maupun kelompok (Purwanto, 2009, hal. 89).

Menurut Dirjen Peningkatan Mutu Pendidik dan Tenaga Kependidikan Departemen Pendidikan Nasional menyatakan bahwasanya supervisi akademik adalah serangkaian proses perbaikan pengajaran yang diawasi serta dinilai oleh kepala sekolah atau pihak yang berwenang dalam mewujudkan suatu pembelajaran secara efektif dan efisien seperti yang diharapkan.

Selain itu, kegiatan ini juga dilakukan untuk meningkatkan segala aspek kompetensi yang salah satunya yakni kompetensi pedagogik. Pedagogik menurut Hoogveld (Belanda) yakni ilmu 
yang mempelajari masalah membimbing siswa ke arah tujuan tertentu, sehingga siswa mampu secara mandiri menyelesaikan tugas hidupnya.

Menurut Standar Nasional Pendidikan, bahwa kompetensi pedagogik guru adalah serangkaian kemampuan guru dalam mengelola proses pembelajaran (Kurniasih \& Sani, 2017, hal. 44). Maksud dari pengertian tersebut yakni guru dikatakan berkompetensi pedagogik adalah guru yang mampu memahami segala bentuk karakteristik peserta didiknya sehingga dengan begitu guru dengan mudah menentukan gaya belajar yang sesuai. Namun disamping itu, masalah sering saja terjadi dalam proses pembelajaran. Sehingga hal itu memberikan pesan penting bagi kepala sekolah selaku pemimpin dalam pengelolaan penyaluran pendidikan untuk melaksanakan kegiatan di bidang supervisi akademik secara rutin guna memberikan segala bimbingan, bantuan, maupun pelayanan sehingga guru dapat dengan mudah memecahkan masalah yang dihadapi pada saat proses pembelajaran. Selain itu, perlunya pengadaan evaluasi dan penilaian atas hasil kinerja guru guna mengetahui peningkatan kompetensi yang dimiliki oleh guru. Maka tujuan utama diadakan kegiatan ini guna meningkatkan kinerja guru serta membangun potensi dalam diri guru untuk meningkatkan mutu pendidikan yang diharapkan.

Berdasarkan penelitian terdahulu yang dilakukan oleh Giarti meningkatkan Kompetensi Pedagogik Guru SD Melalui kegiatan Supervisi Akademik Pada Guru Kelas VI SD Negeri 2 Bengle, Kecamatan Wonosegoro, Kabupaten Boyolali menunjukkan bahwasanya dalam penelitian ini menggunakan penelitian tindakan sekolah dengan lima tahapan.. Adapun tahapannya yakni: perencanaan, pelaksanaan tindakan, observasi, dan refleksi. Penelitian tersebut menggunakan penelitian jenis deskriptif dengan komparasi data. Hasil analisis menunjukkan bahwa tingkat kemampuan guru dalam mengembangkan silabus, menyusun rencana pembelajaran di sekolah tersebut bernilai kurang baik (Giarti, 2015, hal. 43). Sedangkan menurut penelitian lain yang dilakukan oleh Harsiwulan tentang kolaboratif dalam meningkatkan kompetensi pedagogik guru untuk mengembangkan silabus melalui kegiatan supervisi akademik di MI se-Kecamatan Semanu. (Harsiwulan, 2017, hal. 53). Penelitian tersebut dilakukan di tiga MI secara bersiklus/berulang-ulang.

Beberapa penelitian terdahulu diatas, dapat disimpulkan bahwa keberhasilan penyelenggaraan pendidikan ditentukan oleh kemampuan kepala sekolah dalam melakukan pengawasan pada guru dalam mengelola serta mengembangkan silabus dan rencana pelaksanaan pembelajaran guna terlaksananya suatu pembelajaran yang diinginkan. Sehingga hal itu dapat meningkatkan kualitas pendidikan di Indonesia.

Berdasarkan uraian diatas, peneliti menghubungkan dengan kondisi keterlaksanaan kegiatan supervisi akademik di SDN Margorejo VI/524 dan SDN Baratajaya Surabaya. Kedua sekolah tersebut setiap semester sekali telah melakukan supervisi akademik oleh kepala sekolah ataupun oleh pengawas dari UPT (Unit Pelaksanaan Teknis). Selain itu, pengawas juga kerap datang ke 
sekolah untuk melakukan kunjungan tiap kelas dengan melihat hasil dari adanya supervisi akademik yang sudah terlaksana. Dengan tujuan meningkatkan kompetensi pedagogik guru. Sehingga siswa dapat mudah menerima pelajaran yang disampaikan dengan antusiasme yang tinggi.

Hal inilah yang mendorong peneliti untuk meneliti apakah benar terdapat keterlaksanaan supervisi akademik guna meningkatkan kompetensi pedagogik guru. Peneliti melakukan penelitian secara kuantitatif agar mendapatkan hasil kesimpulan yang menyeluruh.

\section{METODE}

Desain penelitian yang digunakan ialah metode penelitian kuantitatif dengan jumlah populasi 102 guru dengan 81 sampel. Penelitian ini dilakukan di SDN Margorejo VI/524 dan SDN Baratajaya Surabaya. Waktu penelitian ini berlangsung selama tiga bulan

Peneliti melakukan penelitian dengan membagikan kuesioner tertutup (angket) kepada 81 responden. Kuesioner tertutup adalah kuesioner yang sudah disediakan jawabannya, sehingga responden diminta untuk memilih jawaban yang sesuai. Terdapat 20 butir soal pada kuesioner supervisi akademik dan 37 butir soal pada kuesioner kompetensi pedagogik guru dengan menggunakan metode skala likert untuk mengukur variabeldalam kuesioner penelitian. Kuesioner yang telah dibuat melalui uji validitas dan uji reliabilitas

Pada penelitian ini teknik analisa data yang digunakan adalah Analisis deskriptif dan analisis korelasi rank spearman. Analisis deskriptif ini digunakan untuk menggambarkan keterlaksanaan supervisi akademik dan kompetensi pedagogik guru di SDN Margorejo VI/524 dan SDN Baratajaya Surabaya. Sedangkan analisis korelasi rank spearman digunakan untuk mencari pengaruh keterlaksanakan supervisi akademik terhadap peningkatan kompetensi pedagogik guru di SDN Margorejo VI/524 dan SDN Baratajaya Surabaya.

\section{HASIL DAN PEMBAHASAN}

Pelaksanaan kegiatan supervisi akademik di SDN Margorejo VI/524 dan SDN Baratajaya Surabaya. berkategori sangat baik hal itu dilihat berdasarakan bagaiamana kepala sekolah benar-benar menguasai dan mampu menerapkan segala bentuk teknik dan prinsip pelaksanaan supervisi akademik dengan menyesuaikan segala permasalahan pendidikan di Indonesia. Sedangkan kompetensi pedagogik guru di SDN Margorejo VI/524 dan SDN Baratajaya Surabaya juga berkategori sangat baik. hal itu dihasilkan dari bagaimana guru tersebut mampu meningkatkan kompetensi pedagogik yang dimilikinya dengan benar-benar menguasai dan melaksanakan aturan yang berpedoman pada Permendiknas No. 16 Tahun 2007.

Hasil tersebut dapat dilihat pada tabel di bawah ini berdasarkan hasil rekapitulasi kuesioner variabel supervisi akademik dan kompetensi pedagogik guru:

\begin{tabular}{|c|c|c|c|c|c|c|c|}
\hline Variabel & N & $\begin{array}{l}\text { Sangat } \\
\text { Ba }\end{array}$ & Baik & Culkup & Rendah & Mean & $\begin{array}{l}\text { Standar } \\
\text { Devias }\end{array}$ \\
\hline & 81 & 49 & 32 & 0 & 0 & 80,80 & $11,273$. \\
\hline $\begin{array}{l}\text { Komptensi } \\
\text { Pedagogik } \\
\text { Gons }\end{array}$ & 81 & 64 & 17 & 0 & 0 & 81,16 & 8,440 \\
\hline
\end{tabular}


Sedangkan untuk mencari adanya pengaruh antara keduanya dapat dilakukan dengan menggunakan uji statistik Spearman rank. Dimana peneliti melakukan perhitungan tersebut melalui bantuan program SPSS versi 21 for windows 2010. Hal itu dilakukan untuk mempermudah peneliti dalam melakukan analisis data yang diperoleh.

Peneliti menggunakan tingkat signifikan 5\% untuk mengetahui korelasi kedua variabel tersebut. jika angka yang diperoleh $<0,05$ maka korelasi keduanya dikatalan signifikan. Namun sebaliknya jika angka yang diproleh > 0,05 maka korelasi keduanya tidak signifikan.

Adapun hasil perhitungan tersebut yakni menunjukkan bahwasanya angka koefisien korelasi spearman rank sebesar 0,608**. Namun nilai signifikan korelasinya sebesar $0,000<0,05$. sehingga hipotesis pada penelitian ini yakni $\mathrm{H}_{1}$ diterima dan $\mathrm{H}_{0}$ ditolak.

\section{SIMPULAN DAN SARAN}

\section{Simpulan}

Berdasarkan hasil penelitian ini, dapat disimpulkan sebagai berikut:

1. Supervisi akademik di SDN Margorejo VI/524 dan SDN Baratajaya Surabaya berkategori sangat baik.

2. Kompetensi pedagogik yang dimiliki oleh guru di SDN Margorejo VI/524 dan SDN Baratajaya Surabaya berkategori sangat baik.

3. Hasil analisis korelasi pada variabel supervisi akademik dan kompetensi pedagogik guru menunjukkan bahwasanya terdapat korelasi sedang terkait adanya pelaksanaan supervisi akademik guna meningkatkan kompetensi pedagogik guru di SDN

\author{
Margorejo VI/524 dan SDN \\ Baratajaya Surabaya.
}

\section{Saran}

Berdasarkan hasil penelitian yang ditemukan mengenai "Pengaruh Pelaksanaan Supervisi Akademik terhadap Peningkatan Kompetensi Pedagogik Guru", peneliti memberikan saran pada pihak-pihak yang terkait berdasarkan permasalahan yang terjadi, antara lain:

1. Kepada sekolah

Pihak institusi sekolah dapat mempertimbangkan adanya kegiatan-kegiatan yang di rencanakan kepala sekolah kepada guru untuk perbaikan pengajarandengan menjadwalkan adanya kegiatan disetiap bulan/tahun agar tujuan yang diinginkan mudah tercapai.Sehingga hal itu dapat menjadikan sebuah institusi sekolah yang bermutu dan berkualitas.

2. Kepada kepala sekolah

Kepala sekolah hendaknya mengupayakan peningkatan kualitas proses dan hasil pembelajaran pada kegiatan supervisi akademik dengan lebih mendorong serta membina guru dalam mengembangkan dan memberi inovasi dalam konteks pembelajaran. Hal itu dimulai dengan bersikap responsif terhadap permasalahan yang sering terjadi sehingga ide kreatif guru dapat tersalurkan secara terbuka. Dengan begitu, kepala sekolah dapat memberikan masukan kepada para guru untuk merubah gaya mengajar yang monoton dengan banyak variasi metode, teknik, 
strategi, dan media yang menunjang proses pembelajaran.

3. Kepada guru

Guru diharapkan mampu menguasai 10 kompetensi inti yang harus dimiliki guru terkait dengan standar kompetensi pedagogis menurut permendiknas No. 16 Tahun 2007 tentang Standar Kualifikasi dan Kompetensi Guru. Selain itu, guru juga diharapkan mampu meningkatkan kualitas pada dirinya dengan mengikuti perkembangan teori pendidikan yang dapat diaplikasikan dalam pelaksanaan proses pembelajaran. Sehingga pola-pola pembelajaran yang dilakukan tidak ketinggalan zaman dan mampu merespon tuntutan perkembangan yang terjadi. Dengan begitu, guru dengan sendirinya akan mampu meningkatkan daya kreatif dalam melaksanakan suatu pembelajaran yang bermakna bagi siswa.

4. Kepada siswa

Siswa diharapkan mampu menggali potensi yang ia miliki dengan menfasilitasi segala bentuk kegiatan yang dapat menampung potensi mereka. Selain itu, siswa mampu belajar dengan baik tanpa paksaan dengan berbagai model kreatif yang di ciptakan oleh guru. Dimana guru yang memiliki kompetensi pedagogik ialah guru yang mampu mengelola suatu pembelajaran yang menarik bagi siswa sehingga siswa tidak merasa terkekang dalam melakukan proses pembelajaran. Dengan begitu, diharapkan siswa mampu meningkatkan hasil belajar dan menggali segala pengetahuan yang ia miliki yang dikembangkan berdasarkan pengalaman siswa.
5. Kepada peneliti lain

Hasil penelitian ini dirasa jauh dari kata sempurna minimal dengan adanya penelitian ini, pihak peneliti lain dapat menambahkannya sebagai tambahan referensi. Selain itu, Peneliti lain diharapkan dapat menyempurnakan hasil penelitian ini dengan hasil penelitian yang ia miliki yang disesuikan dengan kondisi tempat penelitian.

\section{DAFTAR RUJUKAN}

Asmani, J. M. (2012). Tips Efektif Supervisi Pendidikan Sekolah. Jogjakarta: DIVA Press.

Harahap, B. (1983). Supervisi Pendidikan. Jakarta: Damai Jaya.

Harsiwulan, S. D. (2017). Peningkatan Kompetensi Pedagogik Guru dalam Mengembangkan Silabus melalui Supervisi Akademik Kolaboratif di MI se-Kecamatan Semanu. Jurnal Pendidikan Madrasah, 2, 53.

Kurniasih, I., \& Sani, B. (2017). Kupas

Tuntas Kompetensi Pedagogik Teori dan Praktik Untuk Peningkatan Kinerja dan Kualitas Guru. Yogyakarta: Kata Pena.

Permendiknas. (2007). Standar

Kualifikasi Akademik dan

Kompetensi Guru. Jakarta:

Kemendiknas

Purwanto, N. (2009). Administrasi dan Supervisi Pendidikan. Bandung: PT. Remaja Rosdakarya.

Sagala, S. (2009). Kemampuan Proffesional Guru dan Tenaga Kependidikan. Bandung: Alfabeta. 
Fauriza Rohmi, Nafiah - Pengaruh Pelaksanaan Supervisi Akademik Terhadap Peningkatan Kompetensi Pedagogik

Snae, Y. D., Budiati, A. C., \& Heriati, T. (2016). Supervisi Akademik Program Kepala Sekolah Pembelajaran Tahun Keguruan. Jakarta: Rineka Cipta.

Suharsaputra, U. (2014). Metode Penelitian Kuantitatif, Kualitatif, dan Tindakan. Bandung: PT R efika Aditama 

